\title{
Do Racial/Ethnic and Economic Factors Affect the Rate of Complicated Appendicitis in Children?
}

\author{
Abhinav Totapally, ${ }^{1}$ Paul Martinez, ${ }^{2,3}$ Andre Raszynski, ${ }^{2,3}$ Fuad Alkhoury, ${ }^{4}$ \\ and Balagangadhar R. Totapally $\mathbb{D}^{2,3}$ \\ ${ }^{1}$ Texas Children's Hospital, Baylor College of Medicine, Houston, TX, USA \\ ${ }^{2}$ Division of Critical Care Medicine, Nicklaus Children's Hospital, Miami, FL 33155, USA \\ ${ }^{3}$ Herbert Wertheim College of Medicine, Florida International University, Miami, FL 33199, USA \\ ${ }^{4}$ Department of Pediatric Surgery, Nicklaus Children's Hospital, Miami, FL 33155, USA
}

Correspondence should be addressed to Balagangadhar R. Totapally; btotapal@fiu.edu

Received 2 June 2019; Revised 21 May 2020; Accepted 5 June 2020; Published 29 June 2020

Academic Editor: Eelco de Bree

Copyright (C) 2020 Abhinav Totapally et al. This is an open access article distributed under the Creative Commons Attribution License, which permits unrestricted use, distribution, and reproduction in any medium, provided the original work is properly cited.

\begin{abstract}
Introduction. Appendicitis continues to be one of the most common surgical conditions in the pediatric population. We set out to determine demographic and practice variations among children admitted with appendicitis and highlight the racial/ethnic and healthcare access role in relation to the rate of complicated appendicitis using the 2012 Kids' Inpatient Database (KID). Methodology. A retrospective cross-sectional database study was performed using the $2012 \mathrm{KID}$. All children (age 1 months to 20 years) with appendicitis were identified using the ICD-9 diagnosis codes. Children with a diagnosis of appendicitis were compared with all other discharges. Among children with appendicitis, demographic and practice variations and the rate of complicated appendicitis were evaluated. Univariate and multivariate analyses were done to analyze the data. Sample weighing was done to present national estimates. Results. In 2012, a total of 89, 935 out of 2.7 million pediatric hospital discharges (3.3\%) had a diagnosis of appendicitis. The incidence of appendicitis was higher in males (4.7\%), 6-15-year age group (7.43\%), Hispanics (5.2\%), and in the Western region (5.2\%) and was lower in infants $(0.02 \%)$ and African American children $(1.2 \%)(p<0.0001)$. The proportion of children with peritonitis or abscess was higher in children's hospitals (48.2\% vs. 29.0\%; OR 2.3, 95\% CI: 2.2-2.4). The risk of complicated appendicitis was inversely related to age, while racial and ethnic minority status, bottom quartile of the income group, and government insurance increased the risk. Laparoscopic appendectomy was performed more frequently at children's hospitals (84.8\% vs. $74.3 \%$; $p<0.0001)$. Conclusions. Appendicitis is more common in Hispanics, males, older children, and in the Western region. Complicated appendicitis is more common in younger children, minority groups, low-income group, and children with government insurance. Children's hospitals manage more children with complicated appendicitis and are more likely to perform laparoscopic appendectomy.
\end{abstract}

\section{Introduction}

Appendicitis is a common surgical condition with a highest incidence of 23.3 per 10,000 population per year in the 10-19-year age group [1]. The incidence of appendicitis has decreased over the years $[1,2]$. There are age, gender, racial, geographic, and seasonal differences in the incidence of appendicitis [1]. The appendicitis rate is highest among teens and males, and it occurs most frequently during summer months $[1,3]$. In children, complicated appendicitis is relatively common, and the rate of perforated appendicitis varies with age, the presence of obesity, socioeconomic status, and healthcare access [4-9]. Appendicitis may be managed with an open or laparoscopic appendectomy or with medical management and delayed appendectomy. A study from the PHIS database demonstrated an increased trend for laparoscopic appendectomy in children's hospitals [10]. The epidemiology, complications, and treatment of acute appendicitis continue to change [11]. Using the Healthcare Cost and Utilization Project's (HCUP) 2012 
Kids' Inpatient Database (2012 KID), this study explores the recent epidemiology of appendicitis and its management and outcomes in children in the U.S and looks at the factors affecting the risk of complicated appendicitis.

\section{Methods}

2.1. Data Source. The Agency for Healthcare Research and Quality and HCUP data use agreement and training which were completed prior to the KID data set analysis. The research proposal was reviewed by the institutional review board and was deemed exempt and classified as nonhuman subject research. We performed a retrospective analysis of the 2012 KID database to determine demographic and practice variations among children admitted with appendicitis. We compared those variations between children's and non-children's hospitals and examined the variable that may influence the diagnosis of complicated appendicitis. Neonates were excluded from the analysis. Duplicated records were excluded to ensure that we did not count the same patient twice.

2.2. Patient Selection. Children with a diagnosis of appendicitis were extracted from the database, and demographic variables such as gender, race, age groups, income quartiles, region, and urban vs. rural locations were compared with the rest of the discharges. We further subdivided children with appendicitis into four groups: appendicitis with peritonitis, with abscess, without peritonitis, and unspecified using ICD9 codes 540.0, 540.1, 540.9, and 541, respectively. Additionally, we compared surgical management of appendicitis which included laparoscopic appendectomy, nonlaparoscopic appendectomy, and no appendectomy. ICD-9 procedure codes $(47.0,47.01$, and 47.09$)$ were used to extract different surgeries. Those patients who were transferred to another acute care hospital were excluded to avoid double counting. Finally, we examined the incidence, demographics, and surgical practice variations between children and non-children hospitals amongst appendicitis patients.

2.3. Statistical Analysis. We have used chi-square test to analyze categorical variables and multi-chi-square tests for variables with more than two subgroups, such as age groups, race, region, and income. Age-specific trend analysis for incidence of appendicitis, type of surgery, and perforation rate was performed using chi-square trend analysis using Epi Info (CDC, Atlanta, GA).

Patients were grouped into 5 age groups: infants (less than 1 year); $1-5$ years; $6-10$ years; $11-15$ years; and $16-20$ years. HCUP defines median household income (MHI) by the ZIP code in which the child resides. The ZIP codes are stratified by income quartiles with quartile 1 representing the lowest and quartile 4 representing the highest income. Appendicitis with perforation or with abscess was classified as complicated appendicitis, and the remainder were classified as noncomplicated appendicitis. The proportion of complicated appendicitis out of the total number of children with appendicitis discharged from the hospitals was compared among various demographic variables. Race and ethnicity were grouped into White, African American, Hispanic, and others (Asian, Native American, and unknown). Payer status was grouped into government insurance (Medicare and Medicaid), private insurance, and others. Hospital regions were divided into Northeast, Midwest, South, and West. The data were weighted to give national estimates. Multivariate analysis was conducted to determine the adjusted risk of complicated appendicitis.

\section{Results}

In 2012, a total of 89, 935 out of 2.7 million pediatric hospital discharges (3.3\%) had a diagnosis of appendicitis. Nineteen patients died with a mortality rate of $0.021 \%$. Within the appendicitis group, $20.6 \%$ had peritonitis, $12 \%$ had a peritoneal abscess, $64.7 \%$ had no peritonitis, and $3.4 \%$ of cases were unspecified.

3.1. Demographics. Males comprised $59.4 \%$ of all appendicitis patients. The incidence of appendicitis was higher among males (4.65 vs. 2.37 per 100 patients; RR 1.43, 95\% CI: 1.41-1.44). Infants had the lowest rates of appendicitis $(0.1 \%)$, while patients in the 6-10-year and 11-15-year groups had the highest incidence $(7.72 \%$ and $7.42 \%$, respectively; $p<0.0001)$. The incidence was highest in Hispanic patients at 5.19 per 100 patients discharged and lowest in African American patients at 1.18 per 100 patients discharged $(p<0.001)$. Obesity was present in 3.3\% (95\% CI: $3.1-3.3 \%)$ of children discharged with a diagnosis of appendicitis. There was a significant seasonal variation in the incidence of appendicitis with the highest rate in summer months and the lowest rate in winter months $(p<0.0001)$. The incidence of appendicitis was $2.75 \%$ in the lowest quartile $\mathrm{MHI}$ and $4.31 \%$ in the highest quartile $\mathrm{MHI}$ $(p<0.0001)$. The incidence of appendicitis in urban areas was significantly higher than that in rural areas $(3.38 \%$ vs. 2.88\%; RR: $1.17,95 \%$ CI 1.45-1.2, $p<0.001)$. There was a significant regional variation in the incidence of appendicitis with the highest incidence of appendicitis in the West at $5.15 \%$ and the lowest in the Midwest at 2.51\% $(p<0.0001)$. Severe sepsis or septic shock was present in $0.3 \%$ of appendicitis patients, while $0.2 \%$ of children required mechanical ventilation. Table 1 shows demographic details.

Of all cases of appendicitis, $7.28 \%(n=6,514)$ were transferred-in from another acute care hospital. Of the transfer-in cases, $27.68 \%$ and $16.89 \%$ had peritonitis and abscesses, respectively. This is significantly greater than in the nontransfer patients $(p<0.0001)$. An almost equal proportion of both transfer-in and nontransfer cases was managed surgically with an appendectomy (94.41 vs. $90.01 \%)$. As expected, the proportion of transfer-in cases was higher in children's hospitals than compared with nonchildren's hospitals $(25.40 \%$ vs. $15.65 \% ; p<0.0001)$.

3.2. Complicated Appendicitis. Overall, complicated appendicitis was present in $32.4 \%$ of all discharges with appendicitis. On univariate analysis, the proportion of 


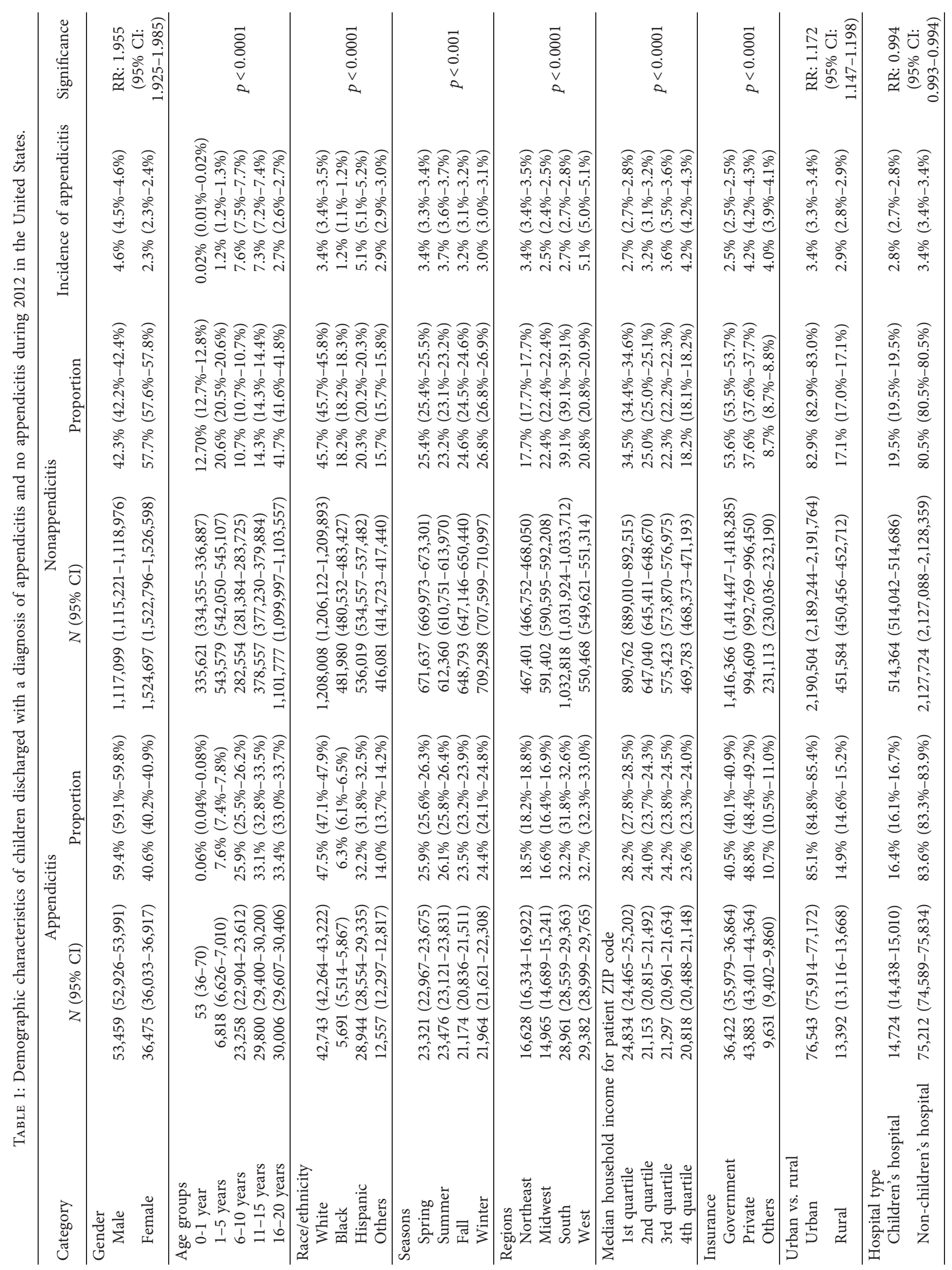


complicated appendicitis was highest in the 1-5-year age group at $61.3 \%$ and lowest in the $16-20$-year age group at $20.9 \%(p<0.0001$; Figure 1$)$. The proportion of children with complicated appendicitis was lowest in the Northeast (25.7\%) and highest in the Midwest (37.7\%) among the four regions of the United States $(p<0.0001)$. The complicated appendicitis rate was lowest in White children $(29.7 \%)$ and highest in the other race/ethnicity groups $(36 \% ; p<0.0001)$. The incidence of complicated appendicitis varied with insurance status. It was lowest in children with private insurance $(29.6 \%)$ and highest in children with government insurance $(36.2 \% ; p<0.0001)$. The incidence of complicated appendicitis was lowest $(28.6 \%)$ in children living in ZIP code areas with 4 th quartile of median household income $(p<0.0001)$. Complicated appendicitis was more common in males compared with females $(33.1 \%$ vs. $31.3 \%$; RR: 1.05 , 95\% CI: $1.03-1.07 ; p<0.0001)$. Children who were discharged from children's hospitals with a diagnosis of appendicitis were more likely to have complicated appendicitis (48.3\% vs. $29.3 \%$; RR: 1.16 , 95\% CI: $1.15-1.18$, $p<0.0001$ ). Table 2 describes the incidence of complicated appendicitis based on various demographic characteristics. Table 3 demonstrates the adjusted risk for complicated appendicitis based on a multivariate analysis. African American, Hispanic, and other racial/ethnic groups compared with White children and younger children ( $0-5$ years) were at higher risk for complicated appendicitis. Having private insurance compared with government insurance, living in ZIP codes with median household income in the 4th quartile compared with the 1st quartile, was associated with a lower risk of complicated appendicitis. All other risk factors are presented in Table 3.

3.3. Management of Appendicitis. Surgical management included laparoscopic appendectomy in $76 \%$ of cases, nonlaparoscopic appendectomy in $18.1 \%$ of cases, and no appendectomy in $5.9 \%$ of cases. Characteristics of children with various surgical approaches are presented in Table 4. Only 1,683 (1.9\%) patients had documentation of antibiotic treatment.

3.4. Children's Hospitals vs. Non-Children's Hospitals. Only $16.4 \%$ of appendicitis cases were managed at a children's hospital, while $83.6 \%$ were managed at non-children's hospitals. The incidence of appendicitis diagnosed at children's hospitals was significantly less than the incidence at non-children's hospitals $(2.81 \%$ vs. $3.47 \%$; RR: $0.994,95 \%$ CI: $0.993-0.994, p<0.0001)$. Approximately $32.05 \%$ and $16.15 \%$ of patients with appendicitis at children's hospitals had peritonitis and abscesses (48.2\% complicated appendicitis), respectively, compared with only $18.07 \%$ and $10.93 \%$ (29\% complicated appendicitis), respectively, of non-children's hospital patients $(p<0.05)$. The most common surgical course for both children's and non-children's hospitals was laparoscopic appendectomy, but laparoscopic surgery was more common at children's hospitals $(84.79 \%$ vs. $74.33 \% ; p<0.0001)$. Nonlaparoscopic/open appendectomy was less common (5.79\% vs. $20.44 \%$ ), and nonsurgical

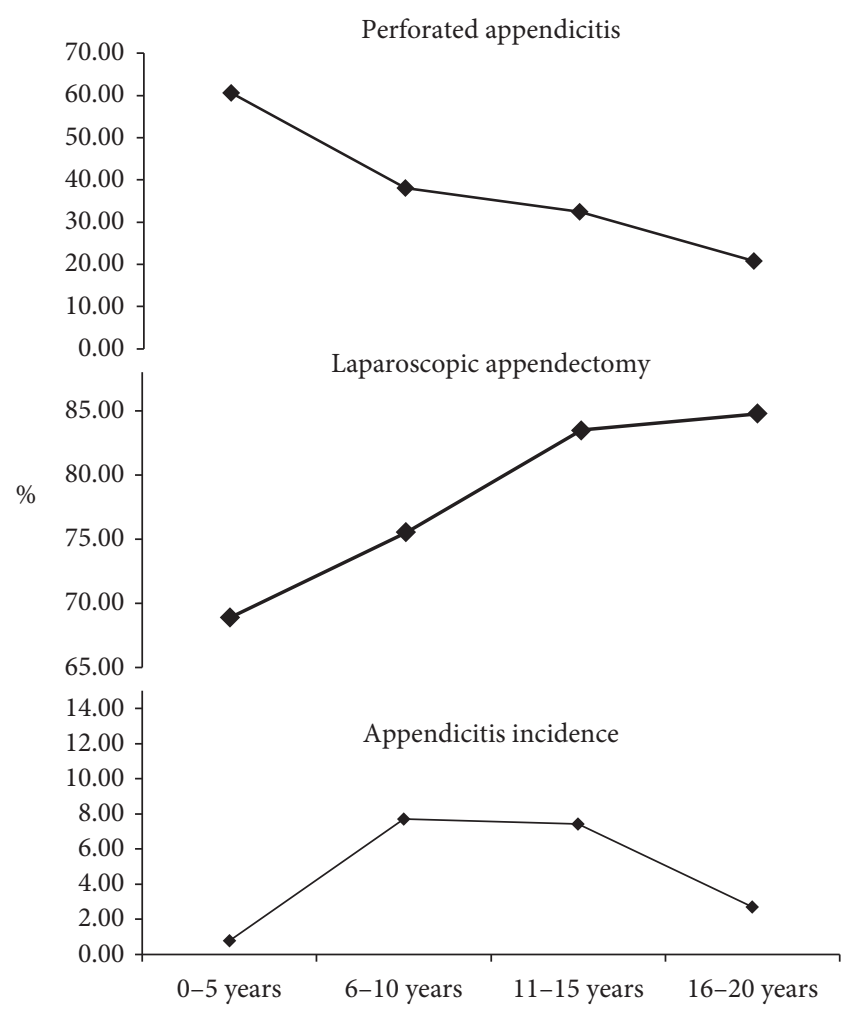

FIgURE 1: Age-specific trends in incidence of appendicitis, appendicitis with peritonitis or abscess, and laparoscopic appendectomy (trend analysis; $p<0.0001$ ).

management was more common (9.43\% vs. $5.23 \%)$ in children's hospitals $(p<0.0001)$.

3.5. Age-Specific Incidence and Complications. As stated earlier, the incidence of appendicitis peaks between ages 6 and 15 years. However, the incidence of complicated appendicitis was highest amongst children aged $0-5$ years at $60.6 \%$. The incidence of complicated appendicitis was inversely related to age. In terms of surgical management, the proportion of laparoscopic appendectomy was directly related to age with ages $16-20$ years demonstrating highest incidence of $81 \%(p<0.0001$; Figure 1).

3.6. Mortality. The overall mortality rate in children with appendicitis was $0.02 \%$ which was lower than the mortality rate in all other discharges (0.31\%; RR: $0.969,95 \% \mathrm{CI}$ : $0.968-0.970, p<0.0001)$.

\section{Discussion}

Our study shows significant regional, seasonal, and agegroup variations in the incidence and complications of appendicitis. Racial/ethnic minorities, children in the lowincome group, and children with government insurance have higher risk of complicated appendicitis. Younger children have a lower incidence of appendicitis, but they present with complicated appendicitis more often. 


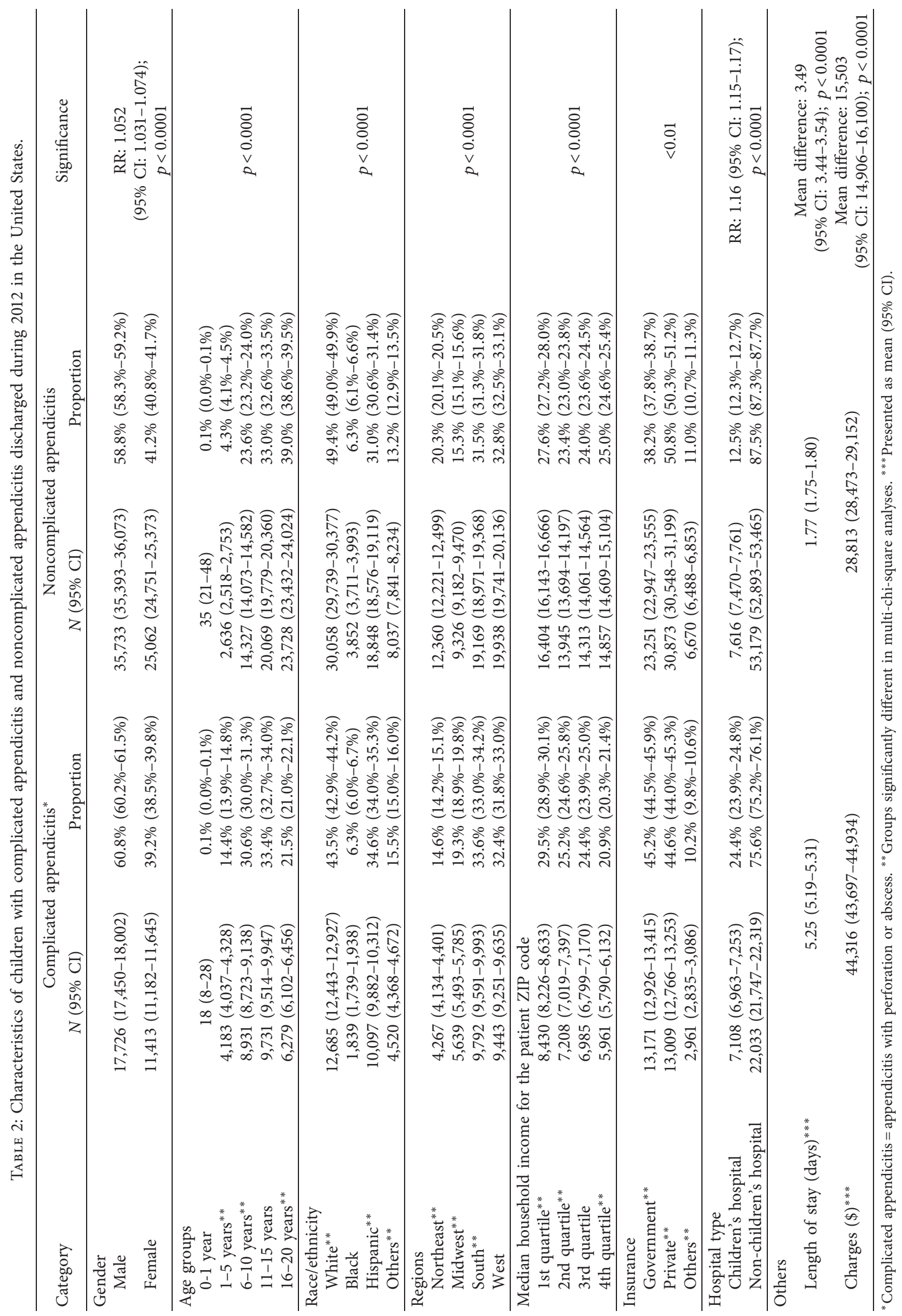


TABLE 3: Multivariable analysis of risk factors for complicated appendicitis.

\begin{tabular}{|c|c|c|c|c|}
\hline \multirow{2}{*}{$\begin{array}{l}\text { Potential risk factors (model } N=62,756 \text { ) } \\
\text { Age groups (ref }=0-5 \text { years) }\end{array}$} & \multirow[t]{2}{*}{ Adjusted odds ratio for complicated appendicitis } & \multicolumn{2}{|c|}{$\begin{array}{c}95 \% \\
\text { confidence } \\
\text { interval }\end{array}$} & \multirow{2}{*}{$\frac{p \text { value }^{*}}{-}$} \\
\hline & & & & \\
\hline $6-10$ years & 0.42 & 0.39 & 0.44 & $<0.001$ \\
\hline $11-15$ years & 0.34 & 0.32 & 0.36 & $<0.001$ \\
\hline $16-20$ years & 0.21 & 0.19 & 0.22 & $<0.001$ \\
\hline Race/ethnicity (ref = White) & & & & - \\
\hline African American & 1.08 & 1.02 & 1.15 & 0.02 \\
\hline Hispanic & 1.07 & 1.03 & 1.11 & $<0.001$ \\
\hline Others & 1.17 & 1.12 & 1.23 & $<0.001$ \\
\hline Female $($ ref $=$ male $)$ & 0.92 & 0.89 & 0.95 & $<0.001$ \\
\hline \multicolumn{5}{|l|}{ Household income quartiles ( $\mathrm{ref}=1$ st quartile) } \\
\hline 2nd quartile & 1.02 & 0.98 & 1.06 & 0.33 \\
\hline 3rd quartile & 0.99 & 0.95 & 1.04 & 0.79 \\
\hline 4th quartile & 0.90 & 0.86 & 0.95 & $<0.001$ \\
\hline \multicolumn{5}{|l|}{ Transfer-in (ref $=$ not a transfer $)$} \\
\hline Transferred from another acute care hospital & 1.39 & 1.32 & 1.47 & $<0.001$ \\
\hline Transferred in from other types of facility & 1.00 & 0.90 & 1.12 & 0.94 \\
\hline Hospital region $($ ref $=$ Northeast $)$ & & & & - \\
\hline Midwest & 1.58 & 1.50 & 1.67 & $<0.001$ \\
\hline South & 1.31 & 1.25 & 1.37 & $<0.001$ \\
\hline West & 1.15 & 1.10 & 1.20 & $<0.001$ \\
\hline Urban/rural (ref = urban) & 0.99 & 0.94 & 1.03 & 0.61 \\
\hline Season $(r e f=$ summer $)$ & & & & - \\
\hline Spring & 1.10 & 1.06 & 1.14 & $<0.001$ \\
\hline Fall & 1.09 & 1.04 & 1.14 & $<0.001$ \\
\hline Winter & 1.08 & 1.04 & 1.13 & $<0.001$ \\
\hline \multicolumn{5}{|l|}{ Insurance (ref = Govt insurance) } \\
\hline Private insurance & 0.94 & 0.91 & 0.97 & $<0.001$ \\
\hline Others & 1.02 & 0.97 & 1.08 & 0.35 \\
\hline Hospital type (ref $=$ non-children's hospital) & 1.70 & 1.64 & 1.77 & $<0.001$ \\
\hline
\end{tabular}

${ }^{*} p$ values calculated from Binary regression.

Laparoscopic appendectomy was performed more often in children's hospitals and in older children.

The incidence of appendicitis was found to be higher in high-income quartiles and in children with private insurance. In contrast, in a study from Taiwan, the incidence of appendicitis and perforation was higher among lowincome population [12]. Racial and ethnic variation in the incidence and complications in our study is similar to a previous study from the KID database [13]. The incidence of appendicitis is lower in African American children compared with Whites and higher in Hispanics compared with Whites. As with our study, the prevalence of complex appendicitis was higher in African Americans and Hispanics compared with White children in a previous study [13].

Higher incidence of appendicitis during summer in our study was similar to that seen in Ontario, Canada [14], in California [15], in the US [1], in Iran [16], in Italy [3], in Nigeria [17], and in Taiwan [18]. Although appendicitis is most common in summer months, rates of perforated appendicitis are highest in fall and winter [8]. The reason for seasonal variation with highest incidence in the summer and the lowest in winter is not known. A possibility of more exposure to infectious agents and allergens during summer months has been suggested [17].
The higher prevalence of complicated appendicitis in younger children as demonstrated in our study has been described previously [9]. The incidence of ruptured appendicitis may be used as a quality indicator for access to care [9]. In the present study, complicated appendicitis was more frequent in lower-income quartiles and in children with government insurance compared with private insurance. Racial/ethnic disparities in access to care may be related to higher prevalence of complicated appendicitis in African American and Hispanic children and other minority groups. Ruptured appendicitis rates were more frequent in African Americans compared with Whites in high-impact areas after Hurricane Katrina, which may be related to racial healthcare disparities [19]. In a study from California and New York, it was found that the odds of ruptured appendicitis was increased by as much as $47 \%$ for African American children, 45\% for Hispanic children, and 116\% for Asian American children compared with that for White children [20]. In our study, nationally, similar findings were observed. Ruptured appendicitis is more common in rural Ohio where the distance to the acute care hospital was greater [21]. Even with universal healthcare, rural and low socioeconomic status are associated with a higher incidence of ruptured appendicitis [6]. Increasing geographic density of pediatricians is associated with a decreasing trend in the 


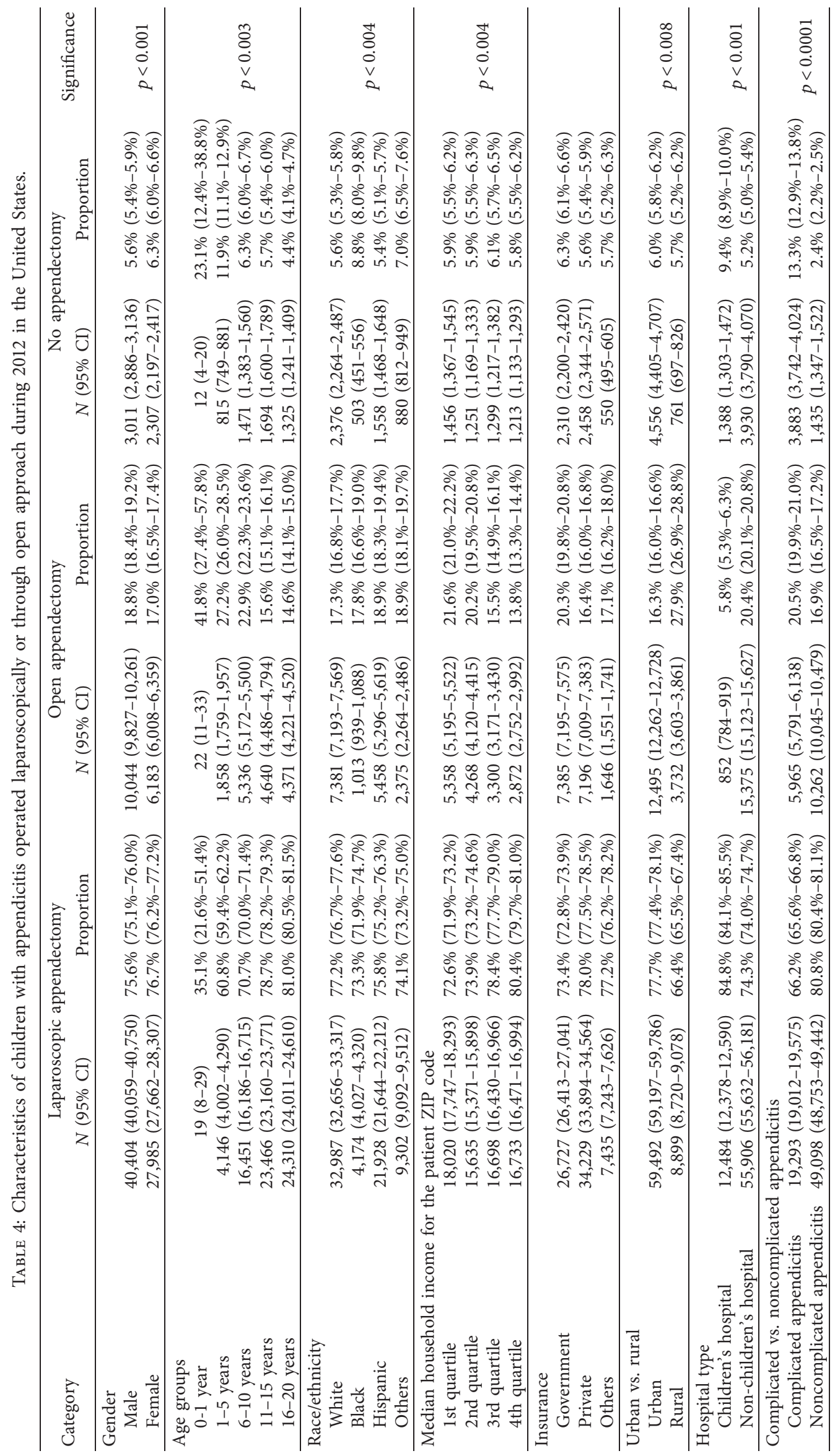


odds ratio of perforated appendicitis [7]. Rural/urban gap in the risk of complicated appendicitis was not observed in our national study. The racial disparities in the incidence of ruptured appendicitis may be more related to access to care and timely referral than disparities in care once the child reaches a hospital [22]. The rate of ruptured appendicitis has been suggested as an indicator for healthcare access [23]. The knowledge of regional, economic, and racial/ethnic variations in the incidence of complicated appendicitis is important with respect to public health preventive measures such as improved healthcare access and preventive care visits.

Although laparoscopic approach has been used in all ages and all stages of appendicitis (noncomplicated, perforated, and appendicitis with abscess), it took longer time for laparoscopic procedure in children compared to the open approach [24]. Laparoscopic appendectomy is at least as safe and effective as, if not superior to, open approach for both simple and perforated appendicitis [25]. Postoperative pain is less, and recovery is faster with laparoscopic approach, thereby reducing LOS and overall cost [25]. Laparoscopic appendectomy has become a procedure of choice in children [25]. Laparoscopic appendectomy was the most common approach used in our study, across age groups, and locations. The use of laparoscopic approach for appendectomy in children has significantly increased in children's hospitals [10]. However, laparoscopic approach was less often used in younger children, in children with complicated appendicitis, and in non-children's hospitals. Surgeon experience of laparoscopic approach in children may account for the variation between children's and non-children's hospitals.

There are several limitations to our study. Due to the retrospective nature and lack of granularity of data collection in an administrative database, we were not able to evaluate specific details of the surgical procedure, antibiotic use, and so on. Because of the cross-sectional nature of the KID database, we were unable to determine long-term complications and readmissions. The extent of coding errors and under-reporting of the prevalence cannot be determined.

\section{Conclusions}

In summary, this retrospective analysis of a large national patient sample describes the epidemiology, regional, seasonal, and racial/ethnic variations in the incidence, complications, and management of acute appendicitis in the US. Acute appendicitis is common in Hispanic children, in older children and early teens, in the Western US region, in the high-income quartile, and during summer months. Complicated appendicitis is more common in racial/ethnic minorities, low-income groups, children with public insurance, and those treated in children's hospital. The knowledge of variation in complicated acute appendicitis across the geography and demographics will help in public health planning.

\section{Abbreviations}

HCUP: Healthcare Cost and Utilization Project
KID: Kids' Inpatient Database

MHI: Median Household Income.

\section{Data Availability}

Data from the Kid's Inpatient Database are used to support the study.

\section{Conflicts of Interest}

The authors declare that there are no conflicts of interest regarding the publication of this paper.

\section{References}

[1] D. G. Addiss, N. Shaffer, B. S. Fowler, and R. V. Tauxe, "The epidemiology of appendicitis and appendectomy in the United States," American Journal of Epidemiology, vol. 132, no. 5, pp. 910-925, 1990.

[2] M. Almström, J. F. Svensson, A. Svenningsson, E. Hagel, and T. Wester, "Population-based cohort study on the epidemiology of acute appendicitis in children in Sweden in 19872013," BJS Open, vol. 2, no. 3, pp. 142-150, 2018.

[3] M. Gallerani, B. Boari, G. Anania, G. Cavallesco, and R. Manfredini, "Seasonal variation in onset of acute appendicitis," Clinical Therapeutics, vol. 157, no. 2, pp. 123-127, 2006.

[4] W. Bonadio, P. Peloquin, J. Brazg et al., "Appendicitis in preschool aged children: regression analysis of factors associated with perforation outcome," Journal of Pediatric Surgery, vol. 50, no. 9, pp. 1569-1573, 2015.

[5] C. L. Garey, C. A. Laituri, D. C. Little, D. J. Ostlie, and S. D. S. Peter, "Outcomes of perforated appendicitis in obese and nonobese children," Journal of Pediatric Surgery, vol. 46, no. 12, pp. 2346-2348, 2011.

[6] I. Bratu, P. J. Martens, W. D. Leslie, N. Dik, D. Chateau, and A. Katz, "Pediatric appendicitis rupture rate: disparities despite universal health care," Journal of Pediatric Surgery, vol. 43, no. 11, pp. 1964-1969, 2008.

[7] M. Camp, D. C. Chang, Y. Zhang et al., "Provider density and health system facility factors and their relationship to rates of pediatric perforated appendicitis in US counties," Archives of Surgery, vol. 145, no. 12, pp. 1139-1144, 2010.

[8] Y. Deng, D. C. Chang, Y. Zhang, J. Webb, A. Gabre-Kidan, and F. Abdullah, "Seasonal and day of the week variations of perforated appendicitis in US children," Pediatric Surgery International, vol. 26, no. 7, pp. 691-696, 2010.

[9] A. Gadomski and P. Jenkins, "Ruptured appendicitis among children as an indicator of access to care," Health services research, vol. 36, no. 1, pp. 129-42, 2001.

[10] A. C. Gasior, S. D. S. Peter, E. M. Knott, M. Hall, D. J. Ostlie, and C. L. Snyder, "National trends in approach and outcomes with appendicitis in children," Journal of Pediatric Surgery, vol. 47, no. 12, pp. 2264-2267, 2012.

[11] S. Aarabi, F. Sidhwa, K. J. Riehle, Q. Chen, and D. P. Mooney, "Pediatric appendicitis in New England: epidemiology and outcomes," Journal of Pediatric Surgery, vol. 46, no. 6, pp. 1106-1114, 2011.

[12] K. B. Lin, C. L. Chan, N. P. Yang et al., "Epidemiology of appendicitis and appendectomy for the low-income population in Taiwan, 2003-2011," BMC Gastroenterol, vol. 15, no. 1, p. 18, 2015.

[13] E. R. Kokoska, T. M. Bird, J. M. Robbins, S. D. Smith, J. M. Corsi, and B. T. Campbell, "Racial disparities in the 
management of pediatric appenciditis," Journal of Surgical Research, vol. 137, no. 1, pp. 83-88, 2007.

[14] M. Al-Omran, M. Mamdani, and R. S. McLeod, "Epidemiologic features of acute appendicitis in Ontario, Canada," Canadian Journal of Surgery, vol. 46, no. 4, pp. 263-268, 2003.

[15] R. Luckmann and P. Davis, "The epidemiology of acute appendicitis in California," Epidemiology, vol. 2, no. 5, pp. 323-330, 1991.

[16] Y. J. Noudeh, N. Sadigh, and A. Y. Ahmadnia, "Epidemiologic features, seasonal variations and false positive rate of acute appendicitis in shahr-e-rey, Tehran," International Journal of Surgery, vol. 5, no. 2, pp. 95-98, 2007.

[17] A. Oguntola, M. Adeoti, and T. Oyemolade, "Appendicitis: trends in incidence, age, sex, and seasonal variations in SouthWestern Nigeria," Annals of African Medicine, vol. 9, no. 4, pp. 213-217, 2010.

[18] P.-L. Wei, C.-S. Chen, J. J. Keller, and H.-C. Lin, "Monthly variation in acute appendicitis incidence: a 10-year nationwide population-based study," Journal of Surgical Research, vol. 178, no. 2, pp. 670-676, 2012.

[19] D. Mack, G. S. Rust, P. Baltrus et al., "Using appendiceal perforation rates to measure impact of a disaster on healthcare system effectiveness," Southern Medical Journal, vol. 106, no. 1, pp. 82-88, 2013.

[20] M. F. Guagliardo, S. J. Teach, Z. J. Huang, J. M. Chamberlain, and J. G. Joseph, "Racial and ethnic disparities in pediatric appendicitis rupture rate," Academic Emergency Medicine, vol. 10, no. 11, pp. 1218-1227, 2003.

[21] R. B. Penfold, D. J. Chisolm, B. C. Nwomeh, and K. J. Kelleher, "Geographic disparities in the risk of perforated appendicitis among children in Ohio: 2001-2003," International Journal of Health Geographics, vol. 7, no. 1, p. 56, 2008.

[22] B. C. Nwomeh, D. J. Chisolm, D. A. Caniano, and K. J. Kelleher, "Racial and socioeconomic disparity in perforated appendicitis among children: where is the problem?" Pediatrics, vol. 117, no. 3, pp. 870-875, 2006.

[23] K. A. Jablonski and M. F. Guagliardo, "Pediatric appendicitis rupture rate: a national indicator of disparities in healthcare access," Population Health Metrics, vol. 3, no. 1, p. 4, 2005.

[24] C.-C. Tsai, S.-Y. Lee, and F.-C. Huang, "Laparoscopic versus open appendectomy in the management of all stages of acute appendicitis in children: a retrospective study," Pediatrics \& Neonatology, vol. 53, no. 5, pp. 289-294, 2012.

[25] T. G. Canty, D. Collins, B. Losasso, F. Lynch, C. Brown, and C. Brown, "Laparoscopic appendectomy for simple and perforated appendicitis in children: the procedure of choice?" Journal of Pediatric Surgery, vol. 35, no. 11, pp. 1582-1585, 2000 . 